\title{
The Use of Smartphones as an Educational Tool in the Classroom: Lecturers' Perceptions
}

\author{
https://doi.org/10.3991/ijet.v15i16.14179
}

\author{
Ahmad Zahir Wali ( $\left.{ }^{\circledR}\right)$, Mohammad Ehsan Omaid \\ Kandahar University, Kandahar, Afghanistan \\ zahirwali@gmail.com
}

\begin{abstract}
Smartphone with its multifunctional features has gained significant importance as a must have gadget of study, work and everyday life. As an emerging trend in educational settings, many institutions are in the process of integrating smartphone into the classroom as a learning tool. This paper aims to study the lecturers' perceptions toward the use of smartphone as an educational tool in classroom. The study also investigates the benefits and perceived barriers of smartphone use by students in classroom from the lecturers' perspective. A quantitative research design was employed and data from a random sample of 50 lecturers of Kandahar University was collected using a questionnaire. The data was analyzed by descriptive statistics using SPSS v24 software. The findings revealed that the lecturers allow the use of smartphone as an educational tool in classroom for all its functions except for the use of social media. The findings also indicated that the lecturers perceive the use of smartphone by the students in classrooms to be beneficial for students in their learning in various ways. Moreover, the findings indicated no major perceived barriers caused by smartphone use in classroom.
\end{abstract}

Keywords-Perceptions, lecturers, smartphone, educational tool, classroom, students' use.

\section{Introduction}

Smartphones are the most powerful technological gadgets of the current time and its multi-functional features have made it a very important part of the everyday routine for almost all people. Smartphones play a very significant role in almost everything an individual does in the day to day work. It is recognized as an important tool of work, entertainment, learning, teaching, etc. In addition to its effectiveness in different aspects of life, smartphones have also been recognized as an important educational tool that facilitates both learning and teaching process in the field of education. According to [2] mobile technology is considered to be the recognized face of educational applications for the recent technologies. Although, many colleges and institutions did not welcome the use of smartphones by students during school hours previously and its use was recognized as a disruption for students' learning, however, with the vast beneficial features that smartphones offer specifically for the benefit of learn- 
ing and teaching, educators and policy makers in the field of education are already recognizing the smartphones as a powerful educational tool that could be used both by the students and teachers to facilitate their learning or teaching process.

In addition, students of the 21 st century are so much attached to the technological trends and it would be hard for them to even imagine not using it in their everyday life. According to [14] students in colleges cannot stand it longer without checking their technological devices such as smartphones, laptops etc. When it comes to technology, students are the usually the first to jump into it and try the new technology and it is most likely that they would do innovation in finding new ways of utilizing the available technology, thus the study of smartphone use among students has to be of particular significance [6].

\subsection{Research objectives}

- To find out whether the lecturers of Kandahar University accept the students' use of smartphones in classes or not.

- To find out the benefits of smartphone use in classroom teaching and learning process based on the lecturers' perception.

- To identify the lecturers' perceived barriers caused by the students' use of smartphones in the classroom.

\subsection{Problem statement}

With all the current technology, smartphone has been one of the must have technological devices of current time. Smartphone users benefit from its multifunctional ability and use it as an important part of their work, study or leisure time. Its use for learning and educational purpose has gained increased attention over the time and efforts are underway to increase its use in classroom environment as a tool for facilitating teaching and learning for both teachers and learners. Although several studies have found the use of smartphone to be effective in facilitating the learning of students in class, still numerous schools, colleges and teachers recognize the use of smartphones in class as a tool of interruption and distraction for students and therefore either prohibits its use completely or show their reluctance for welcoming it as a learning tool [13]. A study by [7] investigated the effects of a smartphone application use in a language communication teaching context and the results showed that students had experienced improvement in their communicative language skill from the use of the smartphone app. The results also indicated that the use of smartphones resulted in reduced students' anxiety. It was also revealed in a study by [12] that older teachers were less likely to show enthusiasm for having smartphones in the classroom for class related purpose and they perceived more barriers of instruction with its integration to class as an educational tool. As no prior or limited research has been conducted to study the perceptions of lecturers at Kandahar University towards the use of smartphone in classes as an education tool, thus this study would provide a better understanding of how the lecturers perceive smartphone as an educational tool in the classroom. 


\section{$2 \quad$ Literature Review}

Modern classes cannot be confined with the traditional bricks and mortar walls, the access to these classes can be done from anywhere and smartphone technology makes it possible for the learners of 21 st century to be engaged in learning while being mobile. This allows the learners to be catered with their own learning style and feel ownership and autonomy for their learning. Smartphone technology also demands educators to be creative in developing pedagogies that would facilitate the integration the technology to classroom learning as an instructional aid [11] [9]. Meanwhile, [1] believes that the success of integrating technology in teaching process greatly depends on the attitudes and willingness of instructors towards accepting technology.

Traditionally perceived as a tool of disruption to the class, instructors who did not allow its use in their classes, had to reconsider their stance as numerous benefits of smartphone use in the classes were evident [10]. With its unique features and characteristics, smartphones' use can make learning and teaching more meaningful and richer [1]. In fact, Google is the new and improved replacement of Encyclopedia for users as a result of smartphone at their fingertips through which everything is available to be searched at any time [15]. [3] consider smartphones as a regular accessory for classroom purpose and accounts educators responsible for giving learners the awareness towards understanding the potential of smartphone use for learning rather than perceiving it as a mean of classroom distraction. The availability of online learning environment in which collaborative learning could happen outside the classroom walls, increased the students' engagement in learning activities and students' motivation are found to be few of the benefits for smartphone use in class [8] [10]. Moreover, [5] revealed that due to reasons of its convenience, portability, comprehensive learning experience, multiple sources, multitasking, and environmental friendliness, students use smartphones as a learning aid.

Students of current technological era arrive on campuses and expect more active and visual learning and they feel comfortable in image rich environment through which they can construct their learning on their own. They have limited tolerance for boredom, memorization and busy work and instead wish to have immediate answers, therefore mobile device facilitate learning also referred to as m-Learning is considered to be a good match for these learners as these devices let them be more active in the process of learning through a learner centered approach, construct their own knowledge and let them gain access to multiple learning resources [13]. Many students not only own smartphones, but they are attached to it, thus many higher education institutes are considering the acceptance of smartphones as an aid to learning [5]. A few years ago, owning a smartphone was considered as a plus point with several advantages to its user, however, a learner not owning one now is considered to be at great disadvantage. In fact, these small devices are possessing the potential to function as a computer while giving the ease of portability as small device, thus giving teachers the potential to use these devices for learning purpose in ways that was a dream few years ago [4].

As smartphone comes with numerous features, it is therefore required that the use of smartphones by student in classes should follow a structured format through which 
they should receive clear and concise guidelines on how to use the smartphones for the intended educational purpose which should function as an aid to their learning [11].

\section{Methodology}

\subsection{Research design}

This is a quantitative research-based survey design study. As the objective of the study was only to study the available trends based on the perceptions of lecturers from various Faculties of Kandahar University towards the use of smartphones as an educational tool in the classroom, therefore, the researcher saw the survey design to be the best research design to guide this study.

\subsection{The instrument}

A questionnaire was developed from available literature and was used as a data collection tool for this study. The questionnaire was shared with a content expert to insure its validity. Several parts of the questionnaire were revised in which additions and omissions were made before it was used for data collection. The questionnaire has four parts. The first part gathered data on the demographic profile of the respondents. The second part had 10 yes/no questions which asked respondents to identify the functions of smartphone that they would or would not allow in their classes. The third part had 12 Likert Scaled Five point based (strongly disagree to Strongly Agree) questions which asked respondents to identify their perceptions toward the benefits of smartphone use in class. The fourth part had nine Likert Scaled Five point-based questions which asked respondents to identify the barriers caused by students' smartphone use in class.

\subsection{Ethical compliance}

To ethically proceed, the approval of each faculty was obtained for the data collection process. The aims of the study were clearly described to each respondent and it was insured to them that the information they provide will be treated only for research purpose and confidentially.

\subsection{Population and sampling}

The population of this study is the lecturers of eleven faculties at Kandahar University located in Kandahar, Afghanistan. A random sample of 50 lecturers from the total 200 population size of lecturers was selected for the study disregarding their demographic data of age, gender, and faculty in which they are working and their work experience. Initially, a sample size of 100 lecturers was chosen for the study, but several of the lecturers did not fill out the questionnaire or partially filled it despite sever- 
al requests were made to have it filled up. Consequently, the researcher was able to have 50 valid filled questionnaires which was selected as the sample size for the study.

\subsection{Demographics of the respondents}

When asked about their work experience, $52 \%$ of the respondents had work experience of 4-7 years, $24 \%$ of the respondents had work experience of 8-11 years, $20 \%$ had the work experience of 1-3 years while only $4 \%$ had the work experience of 12 or more years. When they were asked whether they use smartphone on daily basis or not, $100 \%$ of the respondents replied yes. When they were asked about their age. 96 $\%$ respondents were in the age group of 26-30, Only $2 \%$ respondents were in the age group of 31-35 years, while another $2 \%$ respondents were in the age group of 36-40 years old.

This demographic data shows that majority respondents of this study are young lecturers mostly with limited work experience and all of them owned and used smartphone on daily basis.

\subsection{Reliability}

The reliability of the questionnaire was checked using the Cronbach's alpha calculation of SPSS v24 software. Table 1 shows that a reliability analysis was carried out on the perceived task values scale comprising 29 total items. Cronbach's alpha for the first 9 items of the questionnaire is, $\alpha=0.658$, the second 12 items acquired a score of, $\alpha=0.932$, and the remaining 8 items retained, $a=0.792$ Cronbach's alpha score. All items of the questionnaire appeared to be worthy of retention, resulting in decrease in the alpha if deleted.

Table 1. Reliability of the Questionnaire

\begin{tabular}{|l|c|c|c|}
\hline \multicolumn{1}{|c|}{ Variable } & N of Item & Item Deleted & Alpha \\
\hline Functions of smartphone & 9 & - & 0.658 \\
\hline Benefits of smartphone use in classroom & 12 & - & 0.932 \\
Barriers of smartphone use in classroom & 8 & & 0.792 \\
\hline
\end{tabular}

\subsection{Data analysis}

The data obtained through a questionnaire was analyzed by SPSS v24 software using descriptive statistics by finding the mean scores and standard deviation and frequency along with percentage of the questionnaire items. 


\section{$4 \quad$ Findings}

\subsection{The use of smartphone in classroom}

The first objective of the study was to find out which functions of smartphone do the lecturers of Kandahar University allow to be used in the classes by students. The findings are as present in Table 2 below.

Table 2. Functions of Smartphone

\begin{tabular}{|l|c|c|c|c|}
\hline \multirow{2}{*}{ Functions of Smartphone } & \multicolumn{2}{c|}{ Yes, I allow it } & \multicolumn{2}{c|}{ No, I don't allow } \\
\cline { 2 - 5 } & Frequency & Percent & Frequency & Percent \\
\hline Note Taking & 44 & 88 & 6 & 12 \\
\hline Audio/Video Recorder & 43 & 86 & 7 & 14 \\
\hline Calculator & 41 & 82 & 9 & 18 \\
\hline Use of mobile apps & 39 & 78 & 11 & 22 \\
\hline Browsing the internet/googling & 39 & 78 & 11 & 22 \\
\hline Camera & 30 & 60 & 20 & 40 \\
\hline Texting/Emailing & 29 & 58 & 21 & 42 \\
\hline Alarm/Stop watch/Timer & 29 & 58 & 21 & 42 \\
\hline Accessing Social Media & 16 & 32 & 34 & 68 \\
\hline
\end{tabular}

Table 2 shows that $44(88 \%)$ of the respondents would allow smartphone use in class for "Note taking", 43 (86\%) would allow it for "Audio or Video Recording", 41 $(82 \%)$ would allow it for "Calculator", 39 (78\%) would allow it for the "Use of mobile apps" and "Browsing the internet", 30 (60\%) would allow it for "Camera", 29 $(58 \%)$ would allow it for "Texting/Emailing" and "Alarm/Stop Watch/Timer" . Meanwhile, $34(68 \%)$ of the respondents would not allow the use of smartphone in class for the function of "Accessing Social Media". The findings suggest that majority of the respondents allow the use of smartphones for almost all the functions in the classroom such as notetaking, audio/video recording, calculating, use of mobile apps, internet browsing or googling and using camera, texting/emailing and Alarm/stop watch/timer. However, majority of the respondents would not allow the use of smartphones for Accessing social media.

\subsection{Benefits of smartphone use in classroom}

The second objective of the study aimed to investigate the perceptions of the lecturers with the benefits of smartphone use by students in the class. The specific findings are as present in Table 3 below. 
Table 3. Benefits of smartphone use in classroom

\begin{tabular}{|l|c|c|}
\hline \multicolumn{1}{|c|}{ Benefits of smartphone use in classroom } & Mean & Std. Deviation \\
\hline It helps to find updated information & 4.44 & .972 \\
\hline It increases searching and learning skills & 4.16 & 1.076 \\
\hline It provides anywhere any time learning opportunity & 4.02 & 1.169 \\
\hline It develops digital literacy & 3.90 & .995 \\
\hline It increases productivity & 3.84 & 1.057 \\
\hline It helps to complete assignments on time & 3.82 & 1.101 \\
\hline Increases collaboration & 3.82 & 1.137 \\
\hline It provides opportunity for instruction differentiation & 3.72 & .927 \\
\hline It saves time and increases productivity & 3.62 & 1.159 \\
\hline It increases students' motivation & 3.40 & 1.245 \\
\hline It reduces the digital divide & 3.32 & .819 \\
\hline It increases students' engagement & 3.24 & 1.271 \\
\hline
\end{tabular}

Table 3 shows the mean score for "Benefits of Smartphone Use in Classroom". All of the items had the mean scores between the ranges of three to four. This means that majority of the respondents agree or somewhat agree to all the benefits mentioned in the table above. Items which gained higher mean scores were identified as 'It helps to find updated information' $(\mathrm{M}=4.44, \mathrm{SD}=.972)$, 'It increases searching and learning skills' $(\mathrm{M}=4.16, \mathrm{SD}=1.076)$ and 'It provides anywhere any time learning opportunity' $(\mathrm{M}=4.02, \mathrm{SD}=1.169)$. The findings suggest that overall, the respondents agree that smartphone use in the classroom has the benefits of finding updated information, improving the searching and learning skill, and providing anywhere, anytime learning opportunity. However, the respondents almost agree to the remaining benefits of smartphone use in classroom as mentioned in table 3.

\subsection{Barriers caused by smartphone use in classroom}

The third objective of the study sought to identify the lecturers' perceived barriers against smartphone use by students in the class. The findings are present as in table 4 below.

Table 4. Barriers caused by smartphone use in classroom

\begin{tabular}{|l|c|c|}
\hline \multicolumn{1}{|c|}{ Barriers of smartphone use in classroom } & Mean & Std. Deviation \\
\hline Disconnection of face-to-face activities & 3.80 & 1.143 \\
\hline Cheating & 3.78 & 1.246 \\
\hline Negative impact of SMS language on students writing skill & 3.54 & 1.147 \\
\hline Distraction for other students during class & 3.52 & 1.233 \\
\hline Interference in class & 3.46 & 1.147 \\
\hline Cost of smartphones & 3.42 & 1.144 \\
\hline It would cause socio-economic diversity among students & 3.40 & 1.069 \\
\hline Access of inappropriate content & 3.12 & 1.118 \\
\hline
\end{tabular}

Table 4. shows the mean score for "Barriers caused by Smartphone Use in Classroom". All the items had the mean scores in the range of three. It was deduced that the 
average response of the respondents is "Almost agree". These findings indicate that the respondents only partially agree to all the barriers caused by smartphone use in classroom as presented in table 4 . This means that they don't completely agree that smartphone use in classroom would result in the disconnection of face-to-face activities, cheating, negative impact of SMS language on writing, distraction for other students in class, interference in class, costs of smartphones, cause socio-economic diversity among students or access of inappropriate content.

\section{Discussion}

The results indicated that overall, the lecturers at Kandahar University allow the use of smartphone for almost all its functions in the class except for its use for accessing social media. Since the participants of this study were mostly young aged lecturers, therefore, the overall findings suggest that these lecturers recognize the importance of educational technology especially the use of smartphone as an essential tool for classroom purpose and don't have negative attitude towards integrating technology into classroom environment. [12] found that instructors with older age were more reluctant in having smartphone in class for class related purposes and they believed in the emergence of several barriers due to its use in classroom. According to [1] the successful integration of technology in classroom environment greatly depends on the attitude of the instructor. It was also revealed that the lecturers perceive the use of smartphone by students in the class to be beneficial in various ways. [16] found that smartphone and its apps benefits students in their education and psychology. Smartphone is considered as a must have gadget by both students and teachers, and as teachers' don't perceive the presence of smartphone in class as a mean of interruption as indicated by the findings of this study, it is therefore, suggested that instructors of any discipline should look into any possible ways to integrate smartphone use in their everyday lesson. By doing so, the instructors would have used the most liked technological device of students as a driving force of motivation to engage students in learning. Additionally, the respondents chose not to allow smartphone use in classroom for accessing social media, hence, it is suggested that further research should focus on how social media platforms and apps can be used as a mean of learning aid in classroom.

\section{References}

[1] Papadakis, S. (2018). Evaluating pre-service teachers' acceptance of mobile devices with regards to their age and gender: Acase study in Greece. IJMLO, 12(4), 336-352. https:// doi.org/10.1504/ijmlo.2018.10013372

[2] Kalogiannakis, M., \& Papadakis, S. (2019). Evaluating pre-service kindergarten teachers' intention to adopt and use tablets into teaching practice for natural sciences. International Journal of Mobile Learning and Organisation, 13(1), 113-127. https://doi.org/10.1504/i jmlo.2019.10016617 
[3] Clayton, K., \& Murphy, A. (2016). Smartphone Apps in Education: Students Create Videos to Teach Smartphone Use as Tool for Learning. Journal of Media Literacy Education, 8(2), 99-109.

[4] Leis, A., Tohei, A., \& Cooke, S. D. (2015). Smartphone assisted language learning and autonomy. International Journal of Computer-Assisted Language Learning and Teaching (IJCALLT), 5(3), 75-88. https://doi.org/10.4018/ijcallt.2015070105

[5] Anshari, M., Almunawar, M. N., Shahrill, M., Wicaksono, D. K., \& Huda, M. (2017). Smartphones usage in the classrooms: Learning aid or interference? Education and Information Technologies, 22(6), 3063-3079. https://doi.org/10.1007/s10639-017-9572-7

[6] Emanuel, R. C. (2013). The American college student cell phone survey. College Student Journal, 47(1), 75-81.

[7] Luo, B. R., Lin, Y. L., Chen, N. S., \& Fang, W. C. (2015, July). Using smartphone to facilitate English communication and willingness to communicate in a communicative language teaching classroom. In Advanced Learning Technologies (ICALT), 2015 IEEE 15th International Conference on (pp. 320-322). IEEE. https://doi.org/10.1109/icalt.2015.22

[8] Hee Jin, S. (2014). Implementation of smartphone-based blended learning in an EFL undergraduate grammar course. Officers \& Executive Board, 1(2015), 11. https://doi.org/10. 15702/mall.2014.17.4.11

[9] Kolb, L. (2011). Adventures with cell phones. Educational Leadership, 68(5), 39-43.

[10] Thomas, K. M., O’Bannon, B. W., \& Bolton, N. (2013). Cell phones in the classroom: Teachers' perspectives of inclusion, benefits, and barriers. Computers in the Schools, 30(4), 295-308. https://doi.org/10.1080/07380569.2013.844637

[11] Buck, J. L., McInnis, E., \& Randolph, C. (2013). The new frontier of education: The impact of smartphone technology in the classroom. In American Society for Engineering Education (Vol. 1, No. 1, pp. 1-11).

[12] O'bannon, B. W., \& Thomas, K. (2014). Teacher perceptions of using mobile phones in the classroom: Age matters! Computers \& Education, 74, 15-25. https://doi.org/10.1016/j. compedu.2014.01.006

[13] Robb, M., \& Shellenbarger, T. (2012). Using technology to promote mobile learning: engaging students with cell phones in the classroom. Nurse educator, 37(6), 258-261. https:// doi.org/10.1097/nne.0b013e31826f27da

[14] Yu, F., \& Conway, A. R. (2012). Mobile/smartphone use in higher education. Proceedings of the 2012 Southwest Decision Sciences Institute, 831-839.

[15] Mahesh, G., Jayahari, K. R., \& Bijlani, K. (2016, August). A smart phone integrated smart classroom. In 2016 10th International Conference on Next Generation Mobile Applications, Security and Technologies (NGMAST) (pp. 88-93). IEEE. https://doi.org/10.1109/ ngmast.2016.31

[16] Jesse, G. R. (2015). Smartphone and app usage among college students: Using smartphones effectively for social and educational needs. In Proceedings of the EDSIG Conference (p. n3424). 


\section{Authors}

Ahmad Zahir Wali is a full-time lecturer in the English Language and Literature Department of Education Faculty, Kandahar University. He has obtained Master of Education degree in Teaching English as a Second Language in 2019 from Universiti Teknologi Mara, Shah Alam, Malaysia. (zahirwali@gmail.com)

Mohammad Ehsan Omaid is a full-time lecturer in the Geography Department of Education Faculty, Kandahar University. He got his M.A. in Geography in 2018 from University of Jamia Millia Islamia, New Delhi, India

Article submitted 2020-03-11. Resubmitted 2020-05-17. Final acceptance 2020-05-17. Final version published as submitted by the authors. 